\title{
Effects of Curcuma comosa Roxb. Extract on the Expression of CYP450s in Immortalized Hepatocyte-like Cells (imHC)
}

\author{
Petdao PETCHUAY ${ }^{1}$, Yindee KITIYANANT ${ }^{1}$, \\ Patoomratana TUCHINDA ${ }^{2,8}$, Suradej HONGENG ${ }^{3,8}$, \\ Khanit SA-NGIAMSUNTORN ${ }^{4}$, Vichien KEERATINIJAKAL ${ }^{5}$, \\ Suparerk BORWORNPINYO ${ }^{6,8}$ and Noppawan Phumala MORALES ${ }^{7, *}$
}

\author{
${ }^{I}$ Department of Anatomy, Faculty of Science, Mahidol University, Bangkok 10400, Thailand \\ ${ }^{2}$ Department of Chemistry, Faculty of Science, Mahidol University, Bangkok 10400, Thailand \\ ${ }^{3}$ Department of Pediatrics, Faculty of Medicine, Ramathibodi Hospital, Mahidol University, \\ Bangkok 10400, Thailand \\ ${ }^{4}$ Department of Biochemistry, Faculty of Pharmacy, Mahidol University, Bangkok 10400, Thailand \\ ${ }^{5}$ Department of Agronomy, Faculty of Agriculture, Kasetsart University, Bangkok 10900, Thailand \\ ${ }^{6}$ Department of Biotechnology, Faculty of Science, Mahidol University, Bangkok 10400, Thailand \\ ${ }^{7}$ Department of Pharmacology, Faculty of Science, Mahidol University, Bangkok 10400, Thailand \\ ${ }^{8}$ Excellent Center of Drug Discovery (ECDD), Faculty of Science, Mahidol University, \\ Bangkok 10400, Thailand
}

('Corresponding author's e-mail: noppawan.phu@mahidol.ac.th)

Received: 28 March 2019, Revised: 22 July 2019, Accepted: 19 August 2019

\begin{abstract}
Hepatocytes are the most abundant liver cells that produce biotransformation enzymes, including phase I metabolism enzymes and cytochrome P450s (CYP450s). These enzymes are induced or suppressed by several drugs and chemicals. Here, immortalized hepatocyte-like cells (imHC) were applied as a novel hepatocyte to study the CYP450 enzyme expression induced by a Thai folk herb, Curcuma comosa Roxb. (C. comosa). The results demonstrated that the mRNA expression levels were dependent on cell cultivation conditions, the extract's concentration, and the duration of treatment. In the 3-day cultivation, $1 \mu \mathrm{g} / \mathrm{mL}$ C. comosa extract upregulated the mRNA expression levels of CYP1A1, CYP1A2, CYP2B6, CYP2C9, CYP2D6, CYP2E1 and CYP3A4 in imHC, after treatment for $48 \mathrm{~h}$, which was comparable to the expression levels of those genes in HepG2 cells. In addition, C. comosa increased CYP3A4 protein expression in both imHC and HepG2 cells. Furthermore, $1 \mu \mathrm{g} / \mathrm{mLC}$. comosa could neutralize erythromycin's inhibitory effect, a specific CYP3A4 inhibitor, on CYP3A4 enzyme activity. In conclusion, imHC exhibited several detoxification enzymes, and this cell could be used to replace hepatic carcinoma cells in hepatotoxic studies. The function of C. comosa as a CYP enzyme-inducing agent indicates a promising treatment for the prevention of drug-induced hepatotoxicity by activating detoxification enzymes.
\end{abstract}

Keywords: Curcuma comosa Roxb., Xenobiotic, Detoxification, Immortalized hepatocyte-like cell, Cytochrome P450 


\section{Introduction}

Hepatocytes are prominent liver cells that produce crucial enzymes for detoxification and are involved in xenobiotic and endobiotic biotransformation before elimination from the body $[1,2]$. Biotransformation enzymes are primarily composed of 2 phases: phase I oxidation reactions and phase II conjugating reactions. In phase I, the reactions are involved in the oxidation and reduction of drugs or chemicals that modified toxic substances to the new functional groups and more polarity hydrophilic structures by cytochrome P450s (CYP450s), which play a pivotal role in these processes [3,4].

In hepatotoxicity studies, primary human hepatocytes are the ideal cells used due to their high enzyme expression levels, which indicates a better detoxification ability. However, this cell presents gene expression variations that depend on several factors (i.e., age, behavior and diet). Moreover, their lifespan is short, and these cells need to be freshly isolated. Therefore, hepatic cell lines isolated from human tumors have been utilized for in vitro studies such as HepG2, HepaRG, and BC2 that could grow continuously [5-7]. Although various hepato-specific characteristics and hepatic functions could be maintained for several weeks, they have transformed cells, and their functions frequently vary depending on cell sources [8]. Recently, immortalized hepatocyte-like cells (imHC) have been generated that isolating from bone marrow by using the lentiviral transduction of Bmi-1 and human telomerase reverse transcriptase gene (hTERT) [9]. Consequently, the morphologies, hepato-specific makers, and functions of imHC are distinctly exhibited and have been observed in imHC continuously cultivated for longer than 6 months.

The Thai folk herb Curcuma comosa Roxb. (C. comosa), which is a species in the genus Curcuma belonging to the Zingiberaceae family, commonly known as "Waan chak mod luuk" [10], has been commercially available as a traditional medicine in both crude extracted powder and solution form. Generally, C. comosa is used in traditional medicine for the treatment of hemorrhoids, postpartum uterine bleeding, uterine pain, and inflammation [11,12]. Several in vitro therapeutic activities, including antioxidant activity and antitumor-promoting effects, have been reported and used to treat liver inflammation $[13,14]$. A previous study found that $C$. comosa could protect CCl4-induced toxicity and hepatic functions in male mice by reducing toxic metabolites and activating the detoxification activities involved in the upregulation of CYP2E1 and glutathione-S-transferase (GST) mRNA levels, protein levels, and enzyme activity [15].

Currently, hepatotoxicity and drug interaction are key issues for drug development and clinical trials. Therefore, an in vitro model using Bmi-1/hTERT-induced immortalized hepatocyte-like cells was applied to evaluate herbal medicine's hepatotoxicity and drug development. Here, the potential of $C$. comosa crude extracts as an inducer of the CYP450 enzymes was investigated. Our results may provide the primary information that may serve as the drug development from C. comosa.

\section{Materials and methods}

Materials

All plastic materials and reagents were cell culture grades obtained from Nunc Thermo Fisher Scientific (NY, USA) and Gibco (Invitrogen, NY, USA), respectively. Erythromycin and dimethyl sulfoxide (DMSO) were purchased from Sigma (St. Luis, MO, USA). Cell proliferation was examined by the PrestoBlue ${ }^{\mathrm{TM}}$ Cell Viability Reagent (Invitrogen, NY, USA). RNA extraction was performed with RNeasy Mini kit (Qiagen, CA, USA), a NanoVue Spectrophotometer from GE Healthcare (England, UK) as well as the Luminaris Color HiGreen qPCR Master Mix and Protease Inhibitor Cocktail from Thermo Fisher Scientific (MA, USA). cDNA was prepared by the SuperScript ${ }^{\circledR}$ III First-Strand Synthesis System (Invitrogen, NY, USA). The measuring and blotting instruments were the CFX96 Touch ${ }^{\mathrm{TM}}$ Real-Time PCR detection system (Bio-Rad, CA, USA), Varioskan LUX Multimode Microplate Reader (Thermo Fisher Scientific, MA, USA). Trans-Blot ${ }^{\circledR}$ Turbo $^{\text {TM }}$ transfer system and ChemiDoc ${ }^{\mathrm{TM}}$ Touch Imaging (Bio-Rad, CA, USA). 
http://wjst.wu.ac.th

\section{Compound preparations}

C. comosa was grown at the National Corn and Sorghum Research Center, Kasetsart University, Nakhon Ratchasima, Thailand. The genomic DNA of plant samples was examined to identify Curcuma species [16]. The characteristics of the C. comosa samples that were used in this study included short peduncles ( 2 to $5 \mathrm{~cm}$ in length) and the presence of sessile tubers and master rhizomes. C. comosa was cut into several small pieces, dried, and ground to powder. The $C$. comosa powder was extracted with a hexane extraction method using a Soxhlet extractor, n-hexane solvent distilled from the extract and was exsiccated to obtain the dark brown viscous substance. Diarylheptanoids were reference compounds for quality control. Keeratinijakal and Kongkiatpaiboon [17] described a method of HPLC for determining diarylheptanoids. The $C$. comosa extract compound was dissolved in $100 \mu \mathrm{g} / \mathrm{mL}$ DMSO, and stock solutions were obtained from a 10-fold dilution series in DMSO. The final concentration was $0.1 \%$ DMSO in all culture media.

\section{Cell culture}

The Bmi-1/hTERT-induced human mesenchymal stem cells were previously produced by Sangiamsuntorn et al. [9], which was established from bone marrow isolated cells. Cells were transformed into the immortalized hepatocyte-like cells using lentiviral transduction with the polycomb group transcription factor Bmi-1, and the human telomerase reverse transcriptase gene (hTERT). The Bmi1/hTERT-induced immortalized hepatocyte-like cells (imHC) and human hepatocellular carcinoma cells (HepG2) (Clontech, CA) were cultivated in a T-75 tissue culture flask with maintaining media (Dulbecco's modified Eagle's medium: Nutrient mixture F-12; DMEM/F12), supplemented with $10 \%$ fetal bovine serum (FBS), 100 units/mL GlutaMaxTM and $1 \%$ penicillin/streptomycin at $37{ }^{\circ} \mathrm{C}$ in $5 \%$ CO2. Subconfluent imHC at passages $50-57$ were used in all experiments. In the experiments, the cells were seeded on 6-well plates at a density of 106 cells/well in culture media (William's E media plus $10 \%$ FBS, GlutaMaxTM and penicillin/streptomycin. The media was changed daily until the treatment, which used treatment media (William's E serum-free media plus GlutaMaxTM and pen/strep) with C. comosa and an inhibitor (Erythromycin; Eryc) or inducer (Rifampicin; RIF).

\section{Cell viability}

The imHC was cultured on 96-well plates at a density of $10^{4}$ cells/well in culture media for $24 \mathrm{~h}$. The media was changed to the treatment media with 5 concentrations of $C$. comosa $(0.01,0.1,1,10$ and $100 \mu \mathrm{g} / \mathrm{mL}$ ) for $24 \mathrm{~h}$. Then, PrestoBlue solution was added, and the mixture was incubated for $30 \mathrm{~min}$ at room temperature. Cell viability was analyzed by using a Varioskan LUX Multimode Microplate Reader at the wavelengths of 570 and $600 \mathrm{~nm}$.

\section{RNA extraction and cDNA synthesis}

Total RNA extraction was performed by using an RNeasy Mini-kit according to the manufacturer's instructions. The quality and quantity of the total RNA were determined using a NanoVue Spectrophotometer. For cDNA synthesis, $2 \mu \mathrm{g}$ of each total RNA was converted to cDNA by using SuperScript ${ }^{\circledR}$ III First-Strand synthesis according to the manufacturer's instructions. The cDNA products were stored at $-20^{\circ} \mathrm{C}$ until quantitative real-time PCR analysis. The nontemplate control (non-RT) served as a negative control system.

\section{Quantitative real-time PCR analysis}

All primers were designed using Vector NTI version 10 as shown in Table 1 and ordered from Biolegio (Nijmegen, the Netherlands). All cDNA was amplified by using a Luminaris color HiGreen qPCR master mix and a CFX96 Touch $^{\mathrm{TM}}$ Real-Time PCR detection system. Quantitative real-time PCR was performed by using $500 \mathrm{ng}$ cDNA in a $10 \mu \mathrm{L}$ reaction mixture containing $0.4 \mu \mathrm{M}$ each primer, $5 \mu \mathrm{L}$ HiGreen qPCR master mix, and $4 \mu \mathrm{L}$ RNase-free water. The following protocol was used: $95{ }^{\circ} \mathrm{C}$ for 10 min, followed by 40 cycles of amplification at $95{ }^{\circ} \mathrm{C}$ for $15 \mathrm{~s}, 60^{\circ} \mathrm{C}$ for $40 \mathrm{~s}$, and $72{ }^{\circ} \mathrm{C}$ for $40 \mathrm{~s}$. The fluorescent emissions were examined at the final step of each qRT-PCR cycle. The amplification of genes was measured by using their melting curve from the PCR products. The non-RT (NRT) and nontemplate (NTC) were the negative controls and were included in each primer pair. The fluorescent signal to cross 
the threshold $(\mathrm{Ct})$ of each gene was investigated, and the $\Delta \mathrm{Ct}$ obtained from the $\mathrm{Ct}$ of each gene was subtracted from the $\mathrm{Ct}$ of the housekeeping gene (GAPDH) of the same sample. To calculate $\Delta \Delta \mathrm{Ct}$ used for gene expression comparison, the $\Delta \mathrm{Ct}$ of the treated cell was subtracted from the $\Delta \mathrm{Ct}$ of the untreated cell of the same period. The relative fold change of each gene expression was calculated by $2^{-(\Delta \Delta \mathrm{Ct})}$.

Table 1 Specific primers for phase I enzymes and nuclear transcription factors.

\begin{tabular}{|c|c|c|}
\hline Gene & Strand & Sequence \\
\hline \multirow[t]{2}{*}{ CYP1A1 } & Forward & 5'-CGGCCCCGGCTCTCT-3' \\
\hline & Reward & 5'-CGGAAGGTCTCCAGGATGAA-3' \\
\hline \multirow[t]{2}{*}{ CYP1A2 } & Forward & 5'-TGGAGACCTTCCGACACTCCT-3' \\
\hline & Reward & 5'-CGTTGTGTCCCTTGTTGTGC-3' \\
\hline \multirow[t]{2}{*}{ СУР2B6 } & Forward & 5'-TTAGGGAAGCGGATTTGTCTTG-3' \\
\hline & Reward & 5'-GGAGGATGGTGGTGAAGAAGAG-3' \\
\hline \multirow[t]{2}{*}{ CYP2C9 } & Forward & 5'-GGACAGAGACGACAAGCACA-3' \\
\hline & Reward & 5'-AATGGACATGAACAACCCTCA-3' \\
\hline \multirow[t]{2}{*}{ CYP2C19 } & Forward & 5'-TGCTCTCСТTCTCСTGCTGAAG-3' \\
\hline & Reward & 5'-TGCCAACGACACGTTCAATC-3' \\
\hline \multirow[t]{2}{*}{ CYP2D6 } & Forward & 5'-CTAAGGGAACGACACTCATCAC-3' \\
\hline & Reward & 5'-GTCACCAGGAAAGCAAAGACAC-3' \\
\hline \multirow[t]{2}{*}{ CYP2E1 } & Forward & 5'-TTGAAGCCTCTCGTTGACCC-3' \\
\hline & Reward & 5'-CGTGGTGGGATACAGCCAA-3' \\
\hline \multirow[t]{2}{*}{ CYP3A4 } & Forward & 5'-TGTTTTCAGCCCATCTCCTT-3' \\
\hline & Reward & 5'-TCATTGCATCGAGACAGTTGG-3' \\
\hline \multirow[t]{2}{*}{ AhR } & Forward & 5'-ACATCACCTACGCCAGTCGC-3' \\
\hline & Reward & 5'-TCTATGCCGCTTGGAAGGAT-3' \\
\hline \multirow[t]{2}{*}{ CAR } & Forward & 5'-TGATCAGCTGCAAGAGGAGA-3' \\
\hline & Reward & 5'-AGGCCTAGCAACTTCGCATA-3' \\
\hline \multirow[t]{2}{*}{ PXR } & Forward & 5'-CCAGGACATACACCCCTTTG-3' \\
\hline & Reward & 5'-CTACCTGTGATGCCGAACAA-3' \\
\hline
\end{tabular}




\section{CYP3A4 enzyme activity analysis}

The imHC was cultured on 6-well plates at a density of $10^{6}$ cells/well in culture media for $72 \mathrm{~h}$, followed by treatment media with $0.1 \%$ DMSO, $10 \mu \mathrm{M}$ RIF, $1 \mu \mathrm{g} / \mathrm{mL}$ C. comosa, $40 \mu \mathrm{M}$ erythromycin or $40 \mu \mathrm{M}$ erythromycin plus $1 \mu \mathrm{g} / \mathrm{mL} C$. comosa for $48 \mathrm{~h}$ with daily change. At the end of the experiment, media was changed to treatment media with $3 \mu \mathrm{M}$ Luciferin-IPA (Promega, WI) and incubated for $1 \mathrm{~h}$, followed by luciferin detecting solution for $20 \mathrm{~min}$. Metabolism was performed by luciferase activity, the P450-glo 3A4 assay (Promega, WI) and luminescence was analyzed by using a Varioskan LUX Multimode Microplate Reader.

\section{Protein expression}

RIPA lysis buffer with protease inhibitor cocktail was used to extract total protein lysates. Protein concentrations were examined by using a Pierce bicinchoninic acid (BCA) protein assay kit. To generate a standard curve for the calculation of protein concentration, bovine serum albumin $(2 \mathrm{mg} / \mathrm{mL})$ was used as a standard protein. Total protein concentrations were analyzed by using a microplate spectrophotometer at a wavelength of $652 \mathrm{~nm}$. For gel electrophoresis, $10 \mu \mathrm{g}$ total protein of each sample was separated at $100 \mathrm{~V}$ for $90 \mathrm{~min}$, and the proteins were transferred to polyvinylidene difluoride (PVDF) membranes by using Trans-Blot ${ }^{\circledR}$ Turbo $^{\mathrm{TM}}$ at $25 \mathrm{~V}$ for $7 \mathrm{~min}$. The PVDF membranes were washed with Tris buffered saline plus $0.1 \%$ Tween-20 (TBST) and blocked with $5 \%$ BSA in TBST (blocking solution). Membranes were incubated with rabbit anti-human CYP3A4 primary antibody (Cell Signaling, MA, USA) (diluted 1:1,000 in blocking solution), or rabbit anti-human beta actin antibody (Cell Signaling, MA, USA) (diluted 1:1,000 in blocking solution) overnight at $4{ }^{\circ} \mathrm{C}$. Membranes were incubated with goat anti-rabbit IgG secondary antibody conjugated with horseradish peroxidase (Cell Signaling, MA, USA) (diluted 1:2,000 in blocking solution) at room temperature for $1 \mathrm{~h}$, followed by immersing with Clarity Max ${ }^{\mathrm{TM}}$ Western ECL Substrate (Bio-Rad, CA, USA) for 5 min. CYP3A4 proteins were visualized with chemiluminescence and quantification evaluated with beta actin proteins by ChemiDoc ${ }^{\mathrm{TM}}$ Touch Imaging.

\section{Statistical analysis}

Each experiment was performed in triplicate and in 3 independent experiments except otherwise indicated. Data were compared by using Student's $t$ test and expressed as the mean \pm SD. Multiple data sets were analyzed by one-way analysis of variance (one-way ANOVA), and the differences were determined by Newman-Keuls test. Only $p$-values less than 0.05 were considered statistically significant.

\section{Results}

The effects of $C$. comosa on imHC viability

The imHC was cultivated on 96-well plates for $24 \mathrm{~h}$ followed by culturing in serum-free media with C. comosa at 5 concentrations $(0.01,0.1,1,10$ and $100 \mu \mathrm{g} / \mathrm{mL})$ for $24 \mathrm{~h}$. The treatments of $0.01,0.1$, and $1 \mu \mathrm{g} / \mathrm{mL}$ C. comosa did not affect cell viability (101.2 - 123.6\%). Moreover, the morphologies of the control $(0.1 \%$ DMSO) and imHC treated with $C$. comosa at these concentrations were similar. These cells presented a monolayer of cell clusters with a hexagonal-like shape, clear cytoplasm, and good contact with each other cell. However, at $10 \mu \mathrm{g} / \mathrm{mL} \mathrm{C.} \mathrm{comosa,} \mathrm{cells} \mathrm{were} \mathrm{round} \mathrm{in} \mathrm{shape} \mathrm{and} \mathrm{exhibited} \mathrm{a}$ shrunken and darkened cytoplasm, as well as a loss of contact nearby cells. In the $10 \mu \mathrm{g} / \mathrm{mL} \mathrm{C.} \mathrm{comosa}$ treatment, cells lost their integrity and detached from the cell culture plate. Therefore, the concentrations of C. comosa used in the following experiments were $0.01,0.1$, and $1 \mu \mathrm{g} / \mathrm{mL}$. 


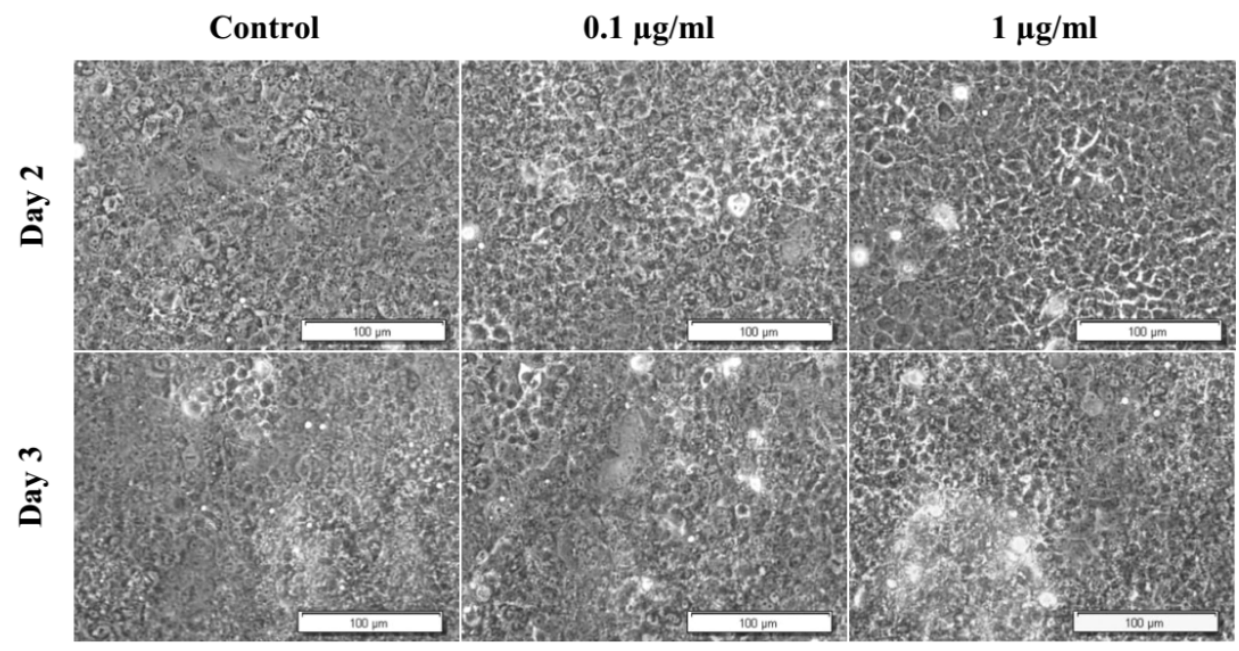

Figure $1 \mathrm{imHC}$ on Day 2 and Day 3 cultivations. Cells were treated with $0.1 \%$ DMSO, 0.1 or $1 \mu \mathrm{g} / \mathrm{mL}$ C. comosa for $24 \mathrm{~h}$. The images were taken at $200 \times$ original magnification.

\section{Effects of $C$. comosa on the dose- and time-dependent cell response in imHC}

Dose-dependent cell response

Here, the cultivation periods of imHC in response to $C$. comosa were compared. imHC were cultivated on 12-well plates for 2 or 3 days, followed by $24 \mathrm{~h}$ serum-free media with $0.01,0.1$ and 1 $\mu \mathrm{g} / \mathrm{mL}$ C. comosa. The morphologies of the control group from the 2-day and 3-day cultivations (Figure 1) were not different from those of all the treatment groups. imHC were a small size with a fully hexagonal-like shape, exhibited tight contact nearby cells and were fully confluent.

The effects of $C$. comosa on the mRNA expression of CYP450s in imHC were measured by using quantitative real-time PCR analysis. At the concentrations of 0.01 and $0.1 \mu \mathrm{g} / \mathrm{mL}, C$. comosa did not alter the expression of CYP450s in either the 2-day or 3-day cultivations (Figure 2). In the $1 \mu \mathrm{g} / \mathrm{mL} C$. comosa-treated group from the 2-day cultivation, only the mRNA levels of CYP1A1 and CYP1A2 were distinctly upregulated. However, the expression levels of CYP1A1, CYP1A2, CYP2B6, CYP2C9 and CYP3A4 were significantly increased from 3-day cultivation. Furthermore, the mRNA expression levels of CYP2B6 and CYP3A4 in the $1 \mu \mathrm{g} / \mathrm{mL} \mathrm{C}$. comosa-treated group from the 3-day cultivation had significantly increased compared with those from the 2-day cultivation. Therefore, these results show that the 3-day cultivation was suitable for studying the mRNA expression of CYP450s in imHC.

\section{Time-dependent cell response}

The lengths of $C$. comosa treatment on the expression of CYP450s in imHC were evaluated. Cells were cultivated on 12-well plates for 3 days, followed by serum-free media with $1 \mu \mathrm{g} / \mathrm{mL}$ C. comosa for 12,24 , or $48 \mathrm{~h}$. The results showed that CYP1A1, CYP1A2 and CYP3A4 mRNA were obviously upregulated at $12 \mathrm{~h}$ after $C$. comosa treatment, while CYP2B6 was certainly upregulated at $24 \mathrm{~h}$. Most of the CYP450s mRNA, including CYP1A1, CYP1A2, CYP2B6, CYP2C9, CYP2E1 and CYP3A4 (except CYP2C19), were significantly upregulated after 48 h of C. comosa treatment (Figure 3). CYP1A1 and CYP1A2 mRNA promptly responded to C. comosa. However, the mRNA levels of these genes were decreased at $24 \mathrm{~h}$. On the other hand, CYP2B6, CYP2C9 and CYP3A4 mRNA were increased as the length of treatment increased in imHC.

The results demonstrated that the mRNA expressions of CYP1A2, CYP2B6, CYP2E1 and CYP3A4 were significantly upregulated. Therefore, the response of imHC to $C$. comosa on those CYP gene 
http://wjst.wu.ac.th

expressions were further compared to that of HepG2, the hepatic carcinoma cells that are widely used in in vitro hepatotoxicity studies.

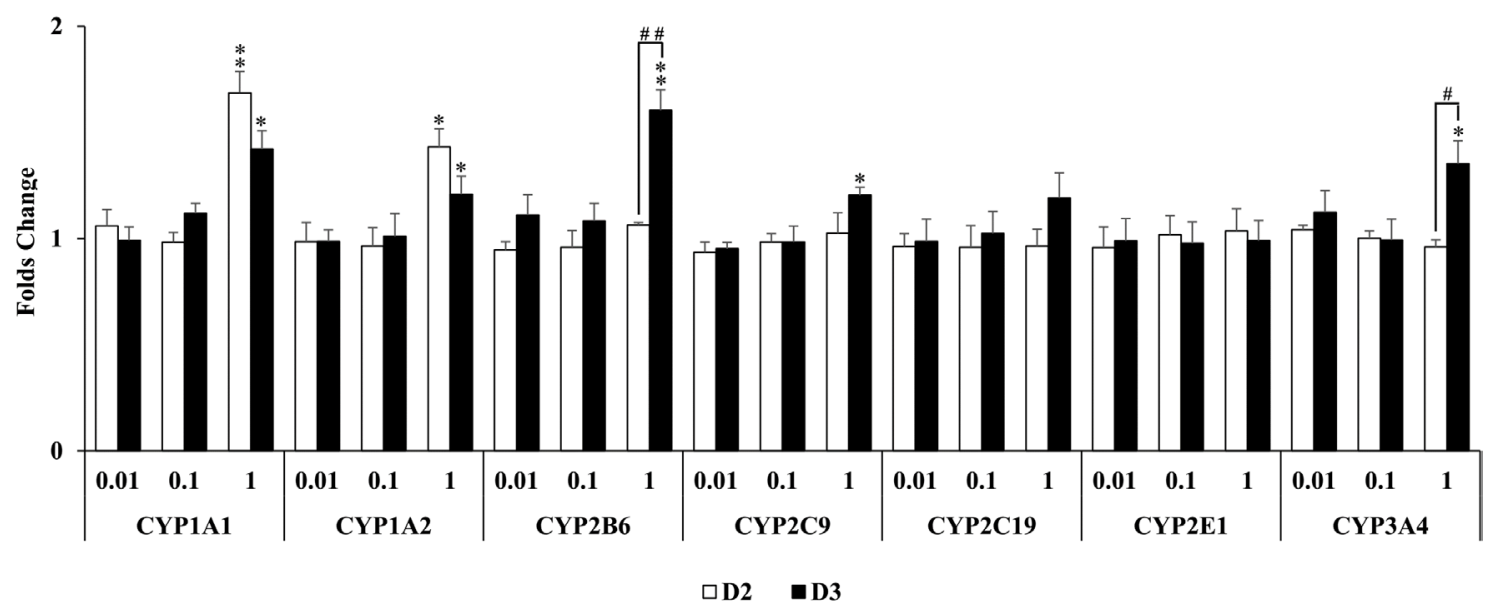

Figure 2 CYP450s mRNA expression of imHC on Day 2 and Day 3 cultivations. Cells were treated with $0.01,0.1$ or $1 \mu \mathrm{g} / \mathrm{mL}$ C. comosa for $24 \mathrm{~h}$. Data are expressed as fold change $(\mathrm{n}=3)$. $* p<0.05, * * p<0.01$ compare with control and ${ }^{\#} p<0.05,{ }^{\#} p<0.01$ compare between groups.

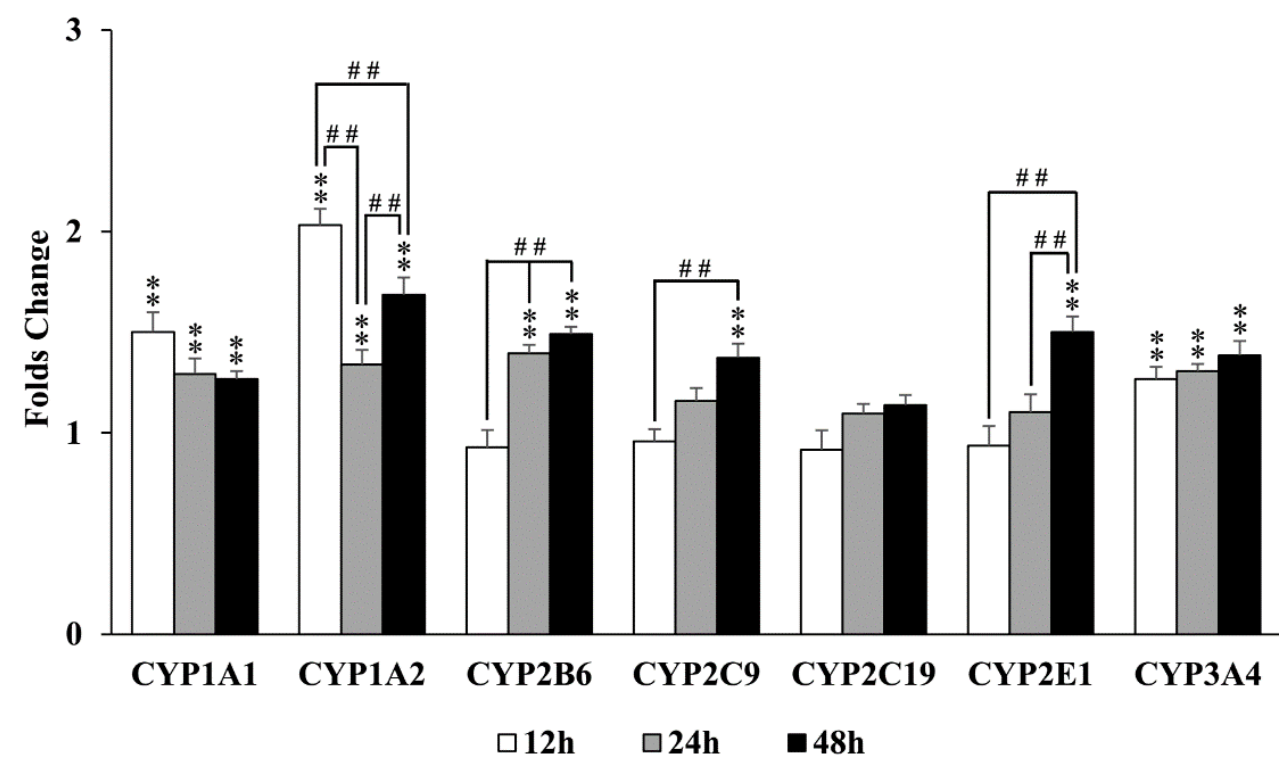

Figure 3 CYP450s mRNA expression of imHC at Day 3 cultivation. Cells were treated with $1 \mu \mathrm{g} / \mathrm{mL} C$. comosa for 12, 24 or $48 \mathrm{~h}$. Data are expressed as fold change $(\mathrm{n}=3)$. ${ }^{* *} p<0.01$ compare with control and ${ }^{\# \#} p<0.01$ compare between groups. 
http://wjst.wu.ac.th

Basal CYP450s, nuclear transcription factors expression and comparison of $C$. comosa treatment in imHC and HepG2

imHC and HepG2 cells were cultivated on 6-well plates for 3 days, followed by serum-free treatment media for $48 \mathrm{~h}$. Basal CYP450s and nuclear transcription factors mRNA expression were analyzed by quantitative real-time PCR. Although the basal mRNA expressions were low, but, both imHC and HepG2 cells also expressed CYP450s isotype including CYP1A1, CYP1A2, CYP2B6, CYP2C9, CYP2C19, CYP2D6, CYP2E1, CYP3A4 and nuclear transcription factors AhR, CAR, PXR (Figure 4). Most basal mRNA expressions were closely similar between imHC and HepG2 cells. When treated with $1 \mu \mathrm{g} / \mathrm{mL}$ C. comosa for $48 \mathrm{~h}$, several CYP450 mRNA expressions were distinctly induced but not nuclear transcription factors in both imHC and HepG2 cells including CYP1A1 (except HepG2), CYP1A2, CYP2B6, CYP2C9, CYP2D6, CYP2E1 and CYP3A4 (Figure 5). Since the drug metabolism, more than $50 \%$ of currently marketed drugs are mediated by CYP3A4 [18]. Therefore, it was decided to focus on CYP3A4 expression as an activating system.

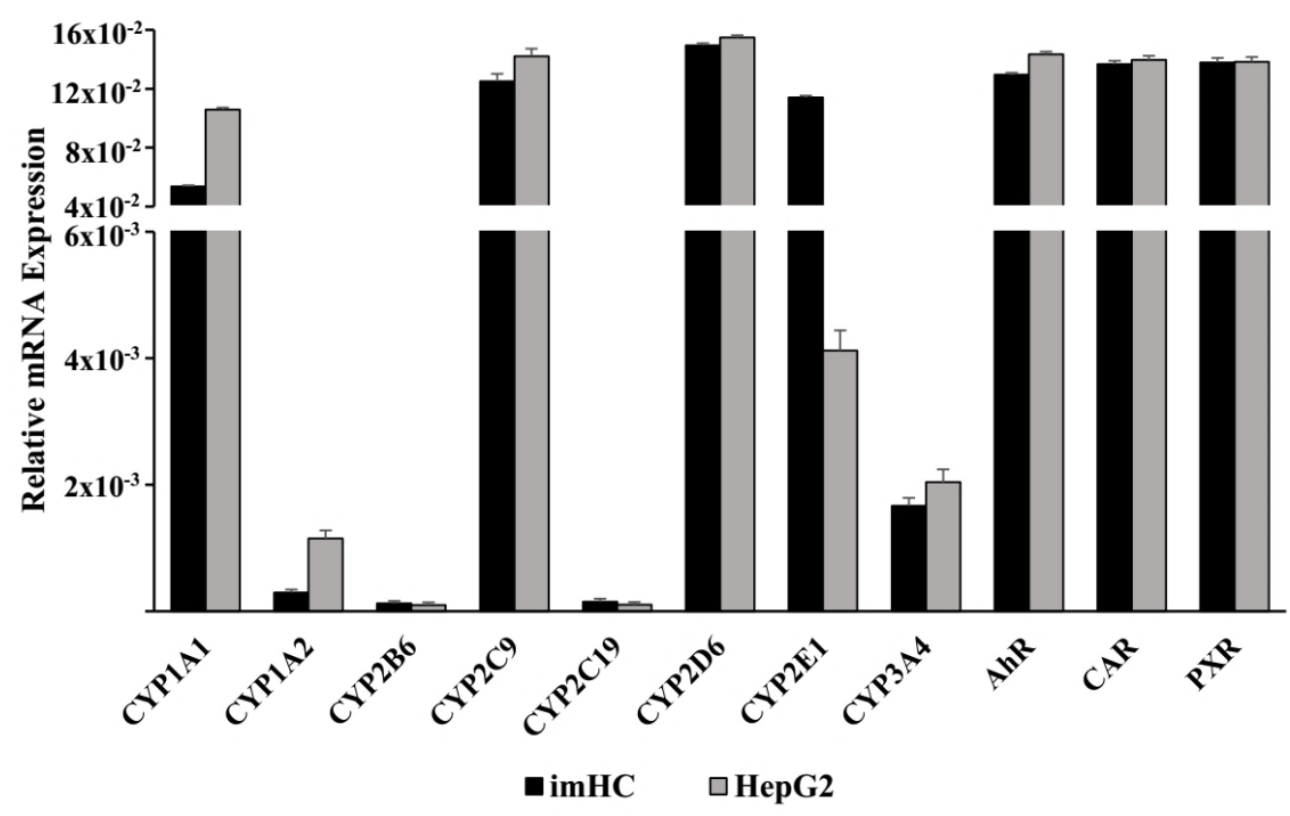

Figure 4 Basal CYP450s mRNA and nuclear transcription factors expression of imHC and HepG2. Basal mRNA expressions are presented as the relative expression levels to those of the house-keeping gene, GAPDH $(n=3)$. 


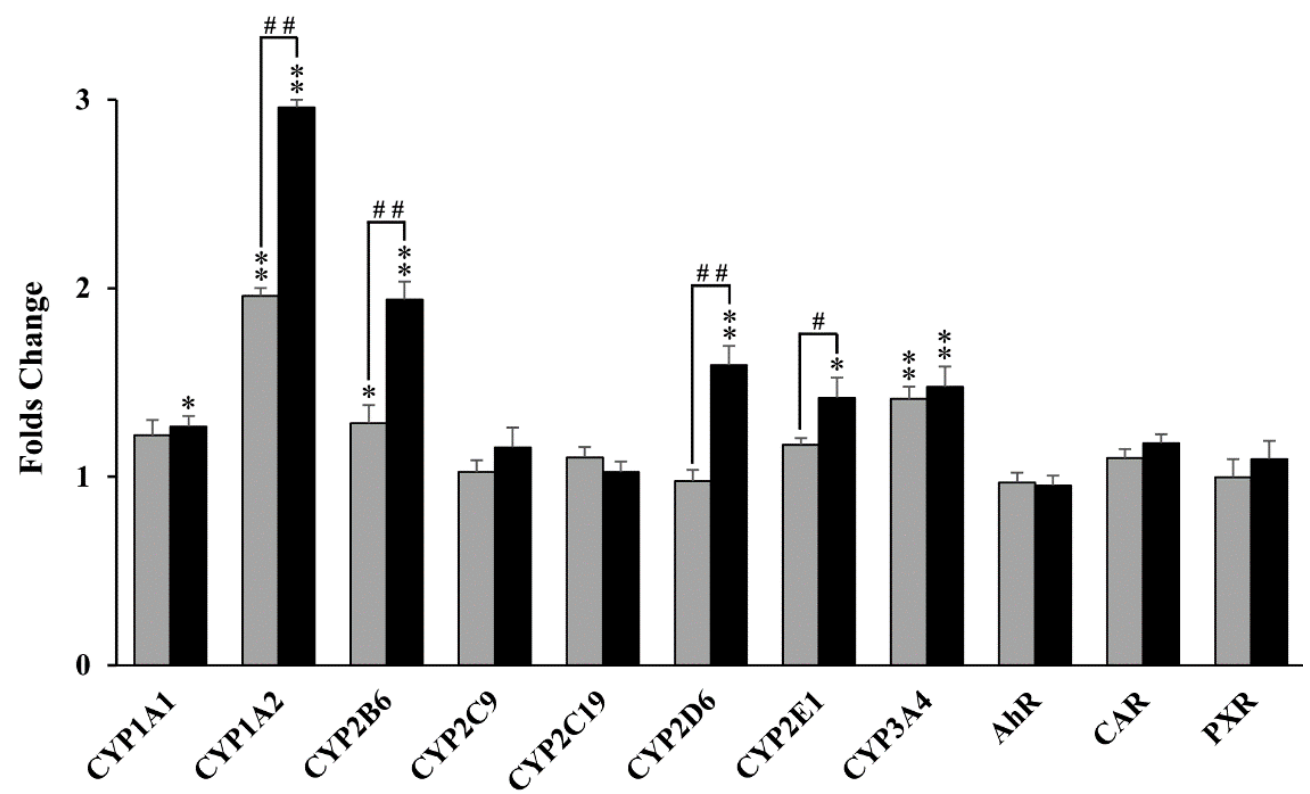

Figure 5 CYP450s mRNA and nuclear transcription factors expression of imHC and HepG2. Cells were treated with $1 \mu \mathrm{g} / \mathrm{mL}$ C. comosa. Data are expressed as fold change $(\mathrm{n}=3)$. ${ }^{*} p<0.05, * * p<0.01$ compare with control and ${ }^{\#} p<0.05,{ }^{\# \#} p<0.01$ compare between groups.

\section{Effects of $C$. comosa and CYP3A4 inducer in imHC and HepG2}

imHC and HepG2 cells were cultivated on 6-well plates for 3 days, followed by serum-free media with $0.1 \%$ DMSO, $10 \mu \mathrm{M}$ RIF or $1 \mu \mathrm{g} / \mathrm{mL}$ C. comosa for 48 h. C. comosa significantly upregulated CYP3A4 mRNA and protein level in both imHC and HepG2 cells (Figures 6 and 7, respectively). Incubation with RIF induced CYP3A4 mRNA induction in HepGe2 and extremely upregulated CYP3A4 mRNA in imHC (Figure 6). 
http://wjst.wu.ac.th

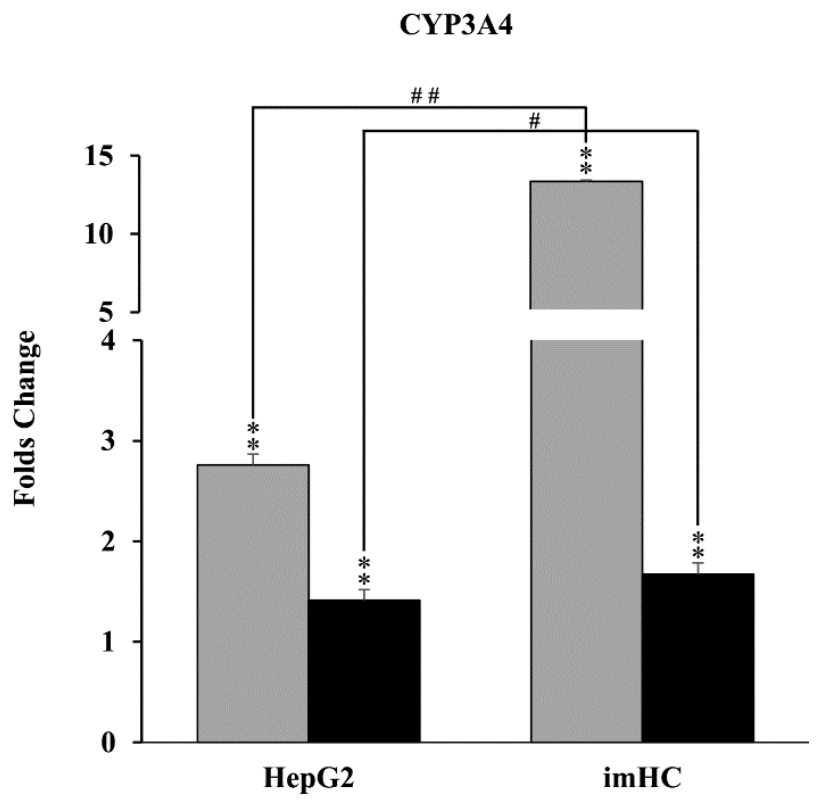

Figure 6 CYP3A4 mRNA expression of imHC and HepG2. Cells were treated with $1 \mu \mathrm{g} / \mathrm{mL}$ C. comosa and $10 \mu \mathrm{M}$ RIF. Data are expressed as fold change $(\mathrm{n}=3)$. ${ }^{* *} p<0.01$ compare with control, ${ }^{\#} p<0.05$ and ${ }^{\# \#} p<0.01$ compare between groups.
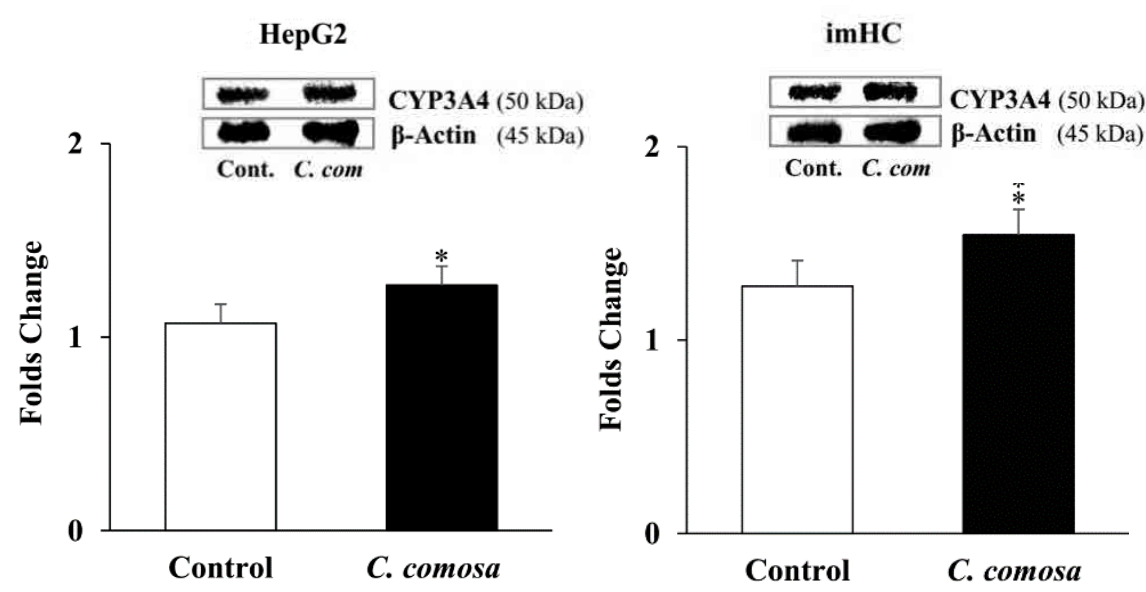

Figure 7 CYP3A4 protein expression $(50 \mathrm{kDa})$ in imHC and HepG2. Cells were treated with $1 \mu \mathrm{g} / \mathrm{mL} C$. comosa. CYP3A4 protein levels were determine by using Western blotting. Data are expressed as fold change $(\mathrm{n}=6) . * p<0.05, * * p<0.01$.

Effects of CYP3A4 enzyme inhibitor and inducer on enzyme activity in $C$. comosa-treated imHC

imHC were cultivated on 6 -well plates for 3 days, followed by serum-free media with $0.1 \%$ DMSO, $10 \mu \mathrm{M}$ RIF, $1 \mu \mathrm{g} / \mathrm{mL}$ C. comosa, $40 \mu \mathrm{M}$ erythromycin or $40 \mu \mathrm{M}$ erythromycin plus $1 \mu \mathrm{g} / \mathrm{mL} C$. comosa for $48 \mathrm{~h}$. Enzyme activities were analyzed by luciferase activity. RIF strongly induced CYP3A4 
http://wjst.wu.ac.th

enzyme level and $C$. comosa treatment also obviously upregulated this enzyme in imHC. When imHC were incubated with a specific CYP3A4 enzyme inhibitor, erythromycin, the downregulation of CYP3A4 activity was observed. However, cotreatment with erythromycin and C. comosa neutralized the inhibitory effect of erythromycin and induced CYP3A4 enzyme level returning to the normal level (Figure 8).

\section{CYP3A4}

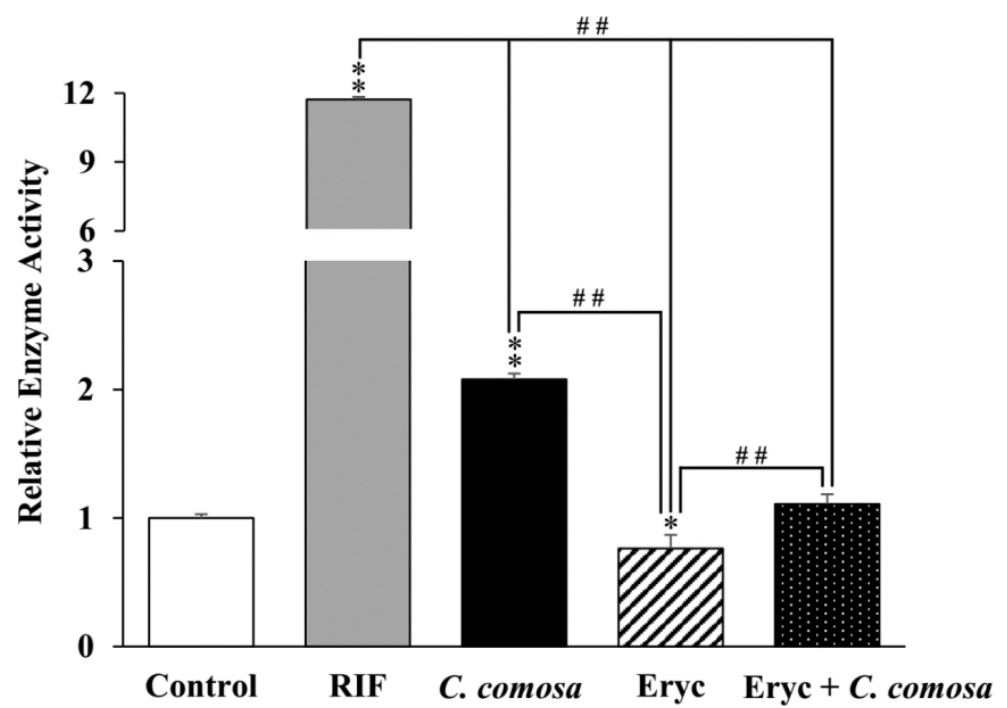

Figure 8 Relative CYP3A4 enzyme activity of imHC. Cells were treated with $0.1 \%$ DMSO, $10 \mu \mathrm{M}$ RIF, $1 \mu \mathrm{g} / \mathrm{mL}$ C. comosa, $40 \mu \mathrm{M}$ erythromycin or $40 \mu \mathrm{M}$ erythromycin plus $1 \mu \mathrm{g} / \mathrm{mL}$ C. comosa. Data are expressed as fold change $(\mathrm{n}=3)$. ${ }^{*} p<0.05$ and ${ }^{* *} p<0.01$ compare with control, ${ }^{\#} p<0.01$ compare between groups.

\section{Discussion}

Since the hepatic carcinoma cells have been successful in the hepatotoxicity studies to substitute for the primary hepatocytes, scientists have tried to develop hepatocyte-like cells to replace these cancer cells. Previously, the Bmi-1/hTERT-induced immortalized hepatocyte-like cells (imHC), which are derived from mesenchymal stem cells (bone marrow as a precursor), have been produced by our team [9]. Although the basal CYP450 expressions were 10 - $40 \%$ of the primary hepatocyte, their specific enzyme inducer responses were highly upregulated. Additionally, the transcription factors that regulate CYP450 isotypes and the phase II enzyme was also observed [9]. Here, we demonstrated that imHC expressed several CYP450 isotypes and their transcription factors, including CYP1A1, CYP1A2, CYP2B6, CYP2C9, CYP2C19, CYP2D6, CYP2E1, CYP3A4, AhR, CAR and PXR. The CYP450 basal levels were similar to those in HepG2 cells. In addition, imHC exhibited upregulated CYP expression in response to an enzyme inducer, RIF, and downregulated CYP enzyme activity in response to an enzyme inhibitor, erythromycin, suggesting that imHC could be suitable for applying to xenobiotic studies.

C. comosa is a widely used traditional Thai herb that most likely interacts with drugs due to its effects on drug metabolism enzymes. In this study, $C$. comosa induced almost all CYP450s mRNA and CYP3A4 protein expressions. Moreover, it neutralized the inhibitory effect of erythromycin on CYP3A4 enzyme activity. C. comosa induced comparable levels of the expression CYP450s, including CYP1A2, CYP2B6, CYP2C9, CYP2D6, CYP2E1 and CYP3A4 mRNA, in both imHC and HepG2, supporting the 
http://wjst.wu.ac.th

application of imHC. C. comosa extract, which has been used in several studies. Weerachayaphorn and colleagues [15,19] reported that $C$. comosa extract has a protective effect against CCl4-induced hepatotoxicity on CYP2E1 and prevented bone loss by estrogen deficiency in mice. Furthermore, the antioxidant activity from $C$. comosa neutralized cisplatin-induced nephrotoxicity [20]. The major component of C. comosa is phytoestrogens, diarylheptanoids [(1,7-diphenyl-(6E)-6-hepten-3-ol) and (1,7diphenyl-(4E,6E)-4,6-heptadien-3-ol)] [21-24].

The $C$. comosa source was grown in Nakhon Ratchasima province containing $23.02 \%$ of diarylheptanoids [17]. The content of diarylheptanoids in this study was slightly lower than that of the previous study, 23.9\%, which originated from Nakhon Pathom province [21]. Diarylheptanoids affected several signaling pathways such as DNA synthesis, the cell number of mouse preosteoblastic cells, and human osteoblasts via Wnt/catenin signaling and MAP kinase activation [24,25]. The anti-apoptotic property of diarylheptanoid suppressed phosphorylated $\mathrm{p} 53$, the $\mathrm{Bax} / \mathrm{Bcl}-2$ ratio and cleaved caspase-3 [26]. C. comosa and diarylheptanoids showed cytotoxic effects at high concentrations, including mechanisms involved in cell apoptosis, the induction of chromatin condensation, the fragmentation of nuclei and DNA [27]. In this study, a suitable concentration of C. comosa was $1 \mu \mathrm{g} / \mathrm{mL}$ at 3-day cultivation enhanced CYP1A1, CYP1A2, CYP2B6, CYP2C9 and CYP3A4 mRNA expression in imHC. The expression of CYPs was increased with the duration of treatment. Cho and coworkers [28] reported that hepatocytes exhibited improved heterotypic cell-cell communication via cytokines and chemokines, enhancing the oxygen supply to the cells in coculture hepatocytes when the cultivation time was extended. Thereby, these results suggested that the duration of treatment was related to the optimal induction time required for the expression of the detoxifying enzymes, and prolonged cultivation time might enhance the expression of CYP450s.

CYP3A4 is a prominent isotype of CYP450 enzymes and performs more than $50 \%$ of the total drug metabolisms in the body and was enhanced by a prototypic inducer, RIF [18,29]. This study showed a low concentration of RIF $(10 \mu \mathrm{M})$ upregulated CYP3A4 mRNA in both imHC and HepG2. Moreover, extreme induction was observed in imHC rather than that in HepG2. These results indicated that the high sensitivity of CYP3A4 enzyme induction in imHC derived from human mesenchymal stem cells was better than that in the hepatic carcinoma cells. In enzyme activity, RIF also induced CYP3A4 enzyme level in imHC. On the other hand, CYP3A4 enzyme activity was suppressed by a specific inhibitor, erythromycin, but when co-incubated with C. comosa, the CYP3A4 enzyme could be restored to the basal level. These phenomena signified that imHC have a high sensitivity to CYP450s induction and C. comosa could be an anti-CYP3A4 suppression that could be used as an anti-drug induce-hepatotoxicity. Generally, CYP3A4 expression is regulated by the pregnane $\mathrm{X}$ receptor (PXR), a ligand-activated transcription factor [30,31]. PXR is activated by several substances, including drugs, chemicals, and xenobiotics [32]. In this study, the 3 analogue CYP450 receptors did not change in response to $C$. comosa. Therefore, the effects of C. comosa were not mediated via the PXR or even other CYP450s receptor. Winuthayanon and colleagues [21] reported that the transcriptional effects of diarylheptanoids from $C$. comosa were directly bound with an ER-dependent pathway involved in the estrogen receptors alpha $(\mathrm{ER} \alpha)$ in HepG2 cells [23]. Thus, the effects of $C$. comosa in this study may be mediated by the ER $\alpha$-induced rather than the PXR-induced activation of CYP3A4 gene transcription.

\section{Conclusions}

The immortalized hepatocyte-like cells (imHC) expressed several CYP450s enzymes and analogue receptors. imHC also induced CPY3A4 mRNA in response to RIF and were suppressed by erythromycin, which neutralized the inhibitory effect by C. comosa. Furthermore, $C$. comosa treatment enhanced several CYP450s mRNA expression and upregulated CYP3A4 mRNA and protein in both imHC and HepG2 cells. Therefore, imHC can be used as a novel cell to replace hepatic carcinoma cells when conducting in vitro studies, and $C$. comosa may be a therapeutic compound evaluated in clinical trials for targeting drug-induced hepatotoxicity. 
http://wjst.wu.ac.th

\section{Acknowledgements}

This project was supported by the Excellent Center of Drug Discovery (ECDD), Faculty of Science, Mahidol University, Thailand.

\section{References}

[1] F Guengerich. Cytochrome P450 enzymes. Am. Sci. 1993; 81, 440-7.

[2] PB Watkins. Role of cytochromes P450 in drug metabolism and hepatotoxicity. Semin. Liver Dis. 1990; 10, 235-50.

[3] F Gonzalez. Molecular genetics of the P450 superfamily. Pharmacol. Ther. 1990; 45, 1-38.

[4] F Guengerich. Cytochrome P450 3A4: Regulation and role in drug metabolism. Ann. Rev. Pharmacol. Toxicol. 1999; 39, 1-17.

[5] C Rodriguez-Antona, MT Donato, A Boobis, RJ Edwards, PS Watts, JV Castell and MJ GomezLechon. Cytochrome P450 expression in human hepatocytes and hepatoma cell lines: Molecular mechanisms that determine lower expression in cultured cells. Xenobiotica 2002; 32, 505-20.

[6] MJ Gómez-lechón, MT Donato, R Jover, C Rodriguez, X Ponsoda, D Glaise, JV Castell and C Guguen-Guillouzo. Expression and induction of a large set of drug-metabolizing enzymes by the highly differentiated human hepatoma cell line BC2. Eur. J. Biochem. 2001; 268, 1448-59.

[7] C Aninat, A Piton, D Glaise, TL Charpentier, S Langouet, F Morel, C Guguen-Guillouzo and A Guillouzo. Expression of cytochromes P450, conjugating enzymes and nuclear receptors in human hepatoma HepaRG cells. Drug Metab. Dispos. 2006; 34, 75-83.

[8] NJ Hewitt and P Hewitt. Phase I and II enzyme characterization of two sources of HepG2 cell lines. Xenobiotica 2004; 34, 243-56.

[9] K Sa-ngiamsuntorn, A Wongkajornsilp, K Kasetsinsombat, S Duangsa-ard, L Nuntakarn, S Borwornpinyo, P Akarasereenont, S Limsrichamrern and S Hongeng. Upregulation of CYP 450s expression of immortalized hepatocyte-like cells derived from mesenchymal stem cells by enzyme inducers. BMC Biotechnol. 2011; 89, 472-87.

[10] T Smitinand. Thai Plant Names. Prachachon, Bangkok, Thailand, 2001.

[11] S Pongboonrod. Mai Thed, Muang Thai. Kasembanakit Press, Bangkok, Thailand, 1976.

[12] M Kurzer and X Xu. Dietary phytoestrogens. Ann. Rev. Nutr. 1997; 17, 353-81.

[13] A Sodsai, P Piyachaturawat, S Sophasan, A Suksamrarn and M Vongsakul. Suppression by Curcuma comosa Roxb. of pro-inflammatory cytokine secretion in phorbol-12-myristate-13-acetate stimulated human mononuclear cells. Int. Immunopharmacol. 2007; 7, 524-31.

[14] N Jantaratnotai, P Utaisincharoen, P Piyachaturawat, S Chongthammakun and Y Sanvarinda. Inhibitory effect of Curcuma comosa on NO production and cytokine expression in LPS-activated microglia. Life Sci. 2006; 78, 571-7.

[15] J Weerachayaphorn, A Chuncharunee, S Jariyawat, B Lewchalermwong, S Amonpatumrat, A Suksamrarn and P Piyachaturawat. Protection of centrilobular necrosis by Curcuma comosa Roxb. in carbon tetrachloride-induced mice liver injury. J. Ethnopharmacol. 2010; 129, 254-60.

[16] V Keeratinijakal, M Kladmook and K Laosatit. Identification and characterization of Curcuma comosa Roxb., phytoestrogens-producing plant, using AFLP markers and morphological characteristics. J. Med. Plants. Res. 2010; 4, 2651-7.

[17] V Keeratinijakal and S Kongkiatpaiboon. Distribution of phytoestrogenic diarylheptanoids and sesquiterpenoids components in Corcuma comosa rhizomes related species. Rev. Bras. Farmacogn. 2017; 27, 290-6.

[18] FP Guengerich. Functional genomics and proteomics applied to the study of nutritional metabolism. Nutr. Rev. 2001; 59, 259-63.

[19] J Weerachayaphorn, A Chuncharunee, C Mahagita, B Lewchalermwongse, A Suksamrarn and P Piyachaturawat. A protective effect of Curcuma comosa Roxb. on bone loss in estrogen deficient mice. J. Ethnopharmacol. 2011; 137, 956-62. 
http://wjst.wu.ac.th

[20] S Jariyawat, P Kigpituck, K Suksen, A Chuncharunee, A Chaovanalikit and P Piyachaturawat. Protection against cisplatin-induced nephrotoxicity in mice by Curcuma comosa Roxb. ethanol extract. J. Nat. Med. 2009; 63, 430-6.

[21] A Suksamrarn, M Ponglikitmongkol, K Wongkrajang, A Chindaduang, S Kittidanairak, A Jankam, BE Yingyongnarongkul, N Kittipanumat, R Chokchaisiri, P Khetkam and P Piyachaturawat. Diarylheptanoids, new phytoestrogens from the rhizomes of Curcuma comosa: Isolation, chemical modification and estrogenic activity evaluation. Bioorg. Med. Chem. 2008; 16, 6891-902.

[22] W Winuthayanon, K Suksen, C Boonchird, A Chuncharunee, M Ponglikitmongkol, A Suksamrarn and P Piyachaturawat. Estrogenic activity of diarylheptanoids from Curcuma comosa Roxb. Requires metabolic activation. J. Agric. Food. Chem. 2009; 57, 840-5.

[23] W Winuthayanon, P Piyachaturawat, A Suksamrarn, M Ponglikitmongkol, Y Arao, SC Hewitt and KS Korach. Diarylheptanoid phytoestrogens isolated from the medicinal plant Curcuma comosa: biologic actions in vitro and in vivo indicate estrogen receptor-dependent mechanisms. Environ. Health Perspect. 2009; 17, 1155-61.

[24] K Bhukhai, K Suksen, N Bhummaphan, K Janjorn, N Thongon, D Tantikanlayaporn, P Piyachaturawat, A Suksamrarn and A Chairoungdua. A phytoestrogen diarylheptanoid mediates estrogen receptor/Akt/glycogen synthase kinase $3 \beta$ protein-dependent activation of the Wnt/ $\beta$ catenin signaling pathway. J. Biol. Chem. 2012; 287, 36168-78.

[25] D Tantikanlayaporn, LJ Robinson, A Suksamrarn, P Piyachaturawat and HC Blair. A diarylheptanoid phytoestrogen from Curcuma comosa, 1,7-diphenyl-4,6-heptadien-3-ol, accelerates human osteoblast proliferation and differentiation. Phytomedicine 2013; 20, 676-82.

[26] J Vattanarongkup, P Piyachaturawat, P Tuchinda, P Sanvarinda, Y Sanvarinda and N Jantaratnotai. Protective Effects of a Diarylheptanoid from Curcuma comosa against hydrogen peroxide-induced astroglial cell death. Planta Med. 2016; 82, 1456-62.

[27] Green R Douglas. Means to an End: Apoptosis and other Cell Death Mechanisms. Cold Spring Harbor Laboratory Press. Cold Spring Harbor, New York, 2011.

[28] CH Cho, J Park, AW Tilles, F Berthiaume, M Toner and ML Yarmush. Layered patterning of hepatocytes in co-culture systems using microfabricated stencils. Biotechniques 2010; 48, 47-52.

[29] S Rendic and FJD Carlo. Human cytochrome P450 enzyme: A status report summarizing their reactions, substrates, induction, and inhibitors. Drug Metab. Rev. 1997; 29, 413-580.

[30] B Blumberg, WJ Sabbagh, H Juguilon, JJ Bolado, CM van Meter, ES Ong and RM Evans. SXR, a novel steroid and xenobiotic-sensing nuclear receptor. Genes Dev. 1998; 12, 3195-205.

[31] JM Lehmann, DD McKee, MA Watson, TM Willson, JT Moore and SA Kliewer. The human orphan nuclear receptor PXR is activated by compounds that regulate CYP3A4 gene expression and cause drug interactions. J. Clin. Invest. 1998; 102, 1016-23.

[32] JT Moore and SA Kliewer. Use of the nuclear receptor PXR to predict drug interactions. Toxicology $2000 ; 153,1-10$. 